\title{
HONOR Y RAZON EN "LA VIDA ES SUEÑO"
}

\author{
Juan Ramon Resina
}

Je vois si manifestement qu'il n'y a point d'indices certains par où l'on puisse distinguer nettement la veille d'avec le sommeil, que j'en suis tout étonné, et mon étonnement est tel qu'il est presque capable de me persuader que je dors ${ }^{1}$.

Car, enfin, soit que nous veillons, soit que nous dormions, nous ne vous devons jamais laisser persuader qu'à l'évidence de notre raison $^{2}$.

Los textos anteriores, de todos conocidos, fueron publicados, respectivamente, en 1641 y en 1637 . No hay que repetir aquí la importancia que tuvieron para el porvenir de Europa y de los países afectados por los modos intelectuales dè aquélla. Solamente España, se ha dicho, fue impermeable al racionalismo, y rechazó, durante tres siglos, las conquistas del individualismo cultivado en Europa desde el Renacimiento. En la obra a que pertenece el segundo de los textos citados, Descartes ha escrito: “... je m'avisai de considérer que souvent il n'y a pas tant de perfection dans les ouvrages composés de plusieurs pièces et faits de la main de divers maîtres qu'en ceux auxquels un seul a travaillé”. En la despedida más explícita que conozco de la cultura medieval, cuya estabilidad, en todos los ámbitos, dependía de la integración y colaboración de elementos y voluntades dispares. No fue otra cosa el feudalismo; no se levantaron de otro modo las catedrales.

Ahora bien, el tema de la meditación de Descartes y la fecha de su publicación están muy próximos a la fecha y al tema de otra meditación, con tono muy diferente, en la España impermeable al racionalismo. Beneficia-

1. René Descartes, Méditations Métaphysiques, Flammarion, Paris, 1937, p. 67.

2. René Descartes, Discours de la Méthode, Flammarion, Paris 1937, p. 26. 
rios ambos de la educación jesuita, Descartes y Calderón se plantean, hacia la misma época, el problema de la realidad de las impresiones, tomando ante esa duda una actitud conforme no sólo a su temperamento personal, sino, especialmente, al del clima espiritual que presiona y da forma a sus pensamientos. Lo que importa es hacer notar que en ambos aparece el sujeto (pensante en Descartes, viviente en Calderón) separado de sus impresiones por la reja de la duda. Las consecuencias, a largo plazo, de esta duda son, claro está, mucho más fecundas para el hombre de ciencia. Pero con la primera reacción tras la inicial pasividad que resulta del hundimiento de la inocencia perceptiva, en la resolución de adoptar un paradigma para el curso de acción ineludible por el hecho de vivir, ambos autores, habiéndose aferrado a principios rectores distintos para no naufragar en la paradoja ("l'evidence de notre raison"; la moralidad, pues "no se pierde/ el hacer bien, aun en sueños" Jor. III, IV, 2400-2401), expresan pareceres pragmáticamente idénticos. Descartes propone la adhesión a las costumbres vigentes, si bien su adhesión está condicionada por la gradual sustitución de la opinión por el conocimiento:

Ainsi, afin que je ne demeurasse point irrésolu en mes actions pendant que la raison m'obligerait de l'être en mes jugements, et que je ne laissasse pas de vivre dès lors le plus hereusement que je purrais, je me formai une morale par provision, qui ne consistait qu'en trois ou quatre maximes dont je veux bien vous faire part.

La première était d'obeir aux lois et aux coutumes de mon pays, retenant constamment la religion en laquelle Dieu m'a fait la gràce d'être instruit dès mon enfance... il me semblait que le plus utile était de me régler selon ceux avec lesquels j'aurais à vivre, et que, pour savoir quelles étaient véritablement leurs opinions, je devais plutôt prendre garde à ce qu'ils pratiquaient qu'à ce qu'ils disaient ${ }^{3} ; \ldots$

La adhesión de Calderón a la opinión dominante en la España de Felipe IV es lo que nos interesa dilucidar a partir de su participación en la forma artística más convencional de la época: el drama de honor.

Si nos proponemos extraer evidencia de La vida es sueño con preferencia a los otros dramas del mismo género, es porque en su obra más ìmportante, Calderón ha problematizado la cuestión del honor junto con todas las demás certidumbres. A fin de no dejar nuestros términos suspendidos en éter, conviene primero tener conciencia del sentido que entrañan. 
Durante el siglo XIX se tuvo la idea, extraña ante lo apremioso de la evidencia en contra, de que el drama de honor era calderoniano. Se había discutido si el drama reflejaba o no las costumbres y psicología españolas del siglo XVII. Algunos autores se preocuparon por el origen del sentimiento honroso, que hacían proceder de los árabes ${ }^{4}$ o de $\operatorname{los}_{\text {godos }}{ }^{5}$, pero no se había revisado la noción de un vacío dramático sobre el que Calderón habría puesto en movimiento sus personajes victimizados por una pasión de orden moral. D.K. Pétrof fue el primero en señalar que, antes de Calderón, Lope había escrito dramas de honor ${ }^{6}$.

Algunas comedias italianas ${ }^{7}$ muestran personajes con sentimientos parecidos a los de los personajes de Calderón, por lo cual Stuart concibió el honor calderoniano como un préstamo italiano ${ }^{8}$. La teoría de Stuart ha sido refutada por Américo Castro ${ }^{9}$, y no es necesario exponer aquí sus argumentos. Baste con uno que es incontrovertible: la cronología. En la Comedia Ymenea (1513-1517) de Bartolomé Torres Naharro está ya presente en forma dramática el conflicto del honor. La opinión de Stuart de que la Ymenea es obra aislada en el teatro del siglo XVI desconoce que la influencia de esta obra fue grande.

La comedia Vidriana (hacia 1550), la comedia Tidea (1550), de Francisco de las Natas, y la comedia Tholomea, de Alonso de la Vega, publicada en 1566, expresan la idea de la venganza como castigo al desliz de la mujer, cuya ligereza ha vulnerado el honor masculino ${ }^{10}$. Otras obras, claramente endeudadas con La Celestina, presentan el rasgo, poco común a las muchas imitaciones de esta obra en el siglo XVI, de conservar el final catastrófico del original. Son la Tragicomedia de Lisandro y Roselia (1542) de Sancho de Muñón, y la Tragedia Policiana (1547) de Sebastián Fernández ${ }^{11}$. También

4. L. de Viel Castel, De l'honneur comme ressort dramatique, (Revue de Deux Mondes, 1841, tomo XXV, pp. 397-421). Cit. por Américo Castro, "Algunas observaciones acerca del concepto del honor en los siglos XVI y XVII", Semblanzas y estudios españoles, Princeton, N.J., 1956, p. 21.

5. G. Ticknor, Historia de la literatura española, IV, 67-68. Citado por Américo Castro, op. cit. , p. 322.

6. D.K. Pétrof, Estudios sobre Lope de Vega (en ruso), 1901. Citado por Américo Castro, op. cit., p. 326.

7. Dolce (Marianna, 1555), Rucellai (Rosmunda), Giraldi (Orbecche, 1541); cit. Américo Castro, op. cit., p. 329.

8. D.C. Stuart, "Honor in the Spanish Drama", Romanic Review, 1910, pp. 247 ss. Cit. Américo Castro, op. cit., pp. 328-329.

9. Ibid., p. 330.

10. Ibid., p. 333 .

11. Donald R. Larson, The Honor Plays of Lope de Vega, Harvard University Press, Cambridge, Massachussetts, 1971, p. 21. 


\section{JUAN RAMON RESINA}

La Numancia de Cervantes, escrita entre 1580 y 1587, pone en primer plano el tema del honor y el recurso a la violencia para salvaguardarlo. Incluso la victimización de las mujeres, para evitar que caigan en manos enemigas, aparece dramatizada como expediente masculino para eludir la deshonra. Por eso no es exacto lo que ha escrito Larson, a tenor de que "when Lope began seriously to write plays, sometime in the middle $1580 \mathrm{~s}$, neither the form nor the ethical content of the honor play was predetermined"12.

C.A. Jones ha puesto en duda que el código del honor expresado en los dramas del Siglo de Oro refleje opiniones o prácticas sociales de la época ${ }^{13}$.

Basta con echar una mirada a lo que escribían los casuistas en el siglo XVI, para darse cuenta de que el honor y la venganza de su ofensa son principios de conciencia tan frecuentes en España, que obligan a que se los considere teóricamente en los tratados para confesores ${ }^{14}$. Y la frecuencia con que aparece el tema durante el siglo XVI, aun fuera de la literatura dramática, muestra ampliamente ser el honor un rector de la vida española de la época. En Persiles y Segismunda, Ortel Banedre quiere dar muerte a su mujer por haberse escapado con su amante. El celoso extremeño, escrita antes de 1606, analiza un caso de honra. Cervantes aporta una comprensión no popular del concepto del honor, relacionándolo con la virtud del individuo, e independizándolo de la opinión ajena. También Mateo Alemán ha tocado la cuestión de la honra en el Guzmán de Alfarache, donde la noción de la deshonra del marido a causa de la veleidad de la mujer es llamada "la opinión de España", hasta tal punto había llegado a permear el principio honroso la conciencia nacional.

Sea cual fuere el origen del principio del honor (aunque se dio en todo Europa durante la Edad Media, su existencia en la España de los Austrias no obedece a ninguna importación, como lo sugiere su formulación, perfectamente definida en las Partidas ${ }^{15}$, lo cierto es que Lope no necesitó inventar este sentimiento. Observando el dominio que ejercía sobre las conciencias, pudo aprovecharlo para recabar el interés del público que acudía a los corrales de comedias.

Es posible que a la difusión del sentimiento honroso contribuyera la popularidad del Romancero, cuyo influjo, junto con el de las Crónicas, sobre el teatro de Lope fue de gran magnitud. "Los temas y el espíritu de la epopeya -escribe Menéndez Pidal- se trasplantan íntegros al teatro. Pues bien, la venganza es el componente esencial de los temas épicos, lo mismo en la

12. Ibid., p. 23.

13. C.A. Jones, introducción a su edición de El médico de su honra, Oxford University Press, 1961, p. xii.

14. Para la exposición de los textos de algunos casuistas, véase A. Castro, op. cit., pp. 350-353.

15. Ramón Menéndez Pidal, De Cervantes y Lope de Vega, Austral, Buenos Aires 1940, p. 166. 
epopeya griega que en la germánica o en la románica"16. La difusión y popularidad del Romancero, así como del espíritu que lo sostiene, obedecía necesariamente a razones de orden sociológico. Américo Castro ha mostrado con pelos y señales cómo la exacerbación del tema del honor en el drama español del Siglo de Oro se inserta en unas condiciones propias exclusivamente de España, que datan de finales del siglo XIV:

Por tan hondo motivo, el "honor" en el drama del siglo XVII no es un simple tema literario, ni un rasgo de psicología humana y universal. Es, sí, expresión de realidad profunda, de la inquietud española por el valer de su persona frente a otras personas, de la inconmovible creencia en su valer personal, afirmada en roces, ajustes y pugnas con otras creencias rivales ${ }^{17}$.

El "hondo motivo" eran las pugnas entre las tres castas de españoles cristianos, judíos, moros- por obtener preeminencia sobre las demás, por alzarse con su orgullo de grupo y hacerse con la hegemonía en la sociedad. El resultado es de todos conocido: el encarnizamiento de la casta cristiana con las otras dos, la expulsión de los judíos y la conversión en masa de muchos de ellos en 1492, el bautismo forzoso de los musulmanes granadinos y de los mudéjares castellanos en 1502, y la expulsión de los moriscos en 1609, reinando Felipe III.

Desde la creación del tribunal de la Inquisición en 1478, asistimos a una progresiva identificación de la idea nacional con la ortodoxia católica. Al orgullo de la casta judía, fundado en la riqueza y la habilidad para hacerse preferir por los príncipes, opone la casta cristiana el orgullo de su tradición guerrera, expresada en la épica y en el romance. Américo Castro ha descrito dos modos de entender la honra: uno es el cuidado y respeto con que se situaba el hombre frente a la opinión, capaz de levantar o arruinar la reputación de la persona; el otro, es el sentimiento de la persona que se sabe honrada, y que inserta este sentimiento en su conciencia de poseer hombría. La hombría era la cualidad de la casta beligerante, aquélla que descendía de los héroes castellanos de la Reconquista y de la expansión del Imperio ${ }^{18}$. Se verá, pues, que la hombría es, propiamente, la vertiente interior de la opinión. Se trata de la vivencia personal de pertenecer a la casta, pertenencia que se vive exteriormente en los signos de honra con que la sociedad reitera la aceptación del individuo. Comprendida dentro de este estrecho marco, resulta aceptable la afirmación de Francisco Ruiz Ramón, aunque sin duda se equivoca en hacer del sentimiento del honor la expresión de una psicología axiológica universal:

16. Ibid.

17. Américo Castro, De la edad conflictiva, $4^{\mathrm{a}}$ edic., Taurus, Madrid 1976, p. 142.

18. Ibid., pp. 23-26. 
Esta dramatización de los "casos de honra" significa, pues, una exaltación del hombre común como persona y como personaje. Que la personalidad humana, que el sentimiento personal de sí mismo, adquiera máxima intensidad en su formulación, es fruto natural del Renacimiento ${ }^{19}$.

El hombre común exaltado al rango de personaje honrado, capaz de sentir y conocer su propio valer, no era cualquier hombre; era el cristiano viejo, el campesino castellano, orgulloso de su linaje impoluto por sangre judía o mora, y arrogante de sus costumbres y de su tradición guerrera, documentadas en el Romancero y las Crónicas, arcón de temas de donde Lope extrajo los materiales con que se dio forma al teatro nacional.

Cuando Calderón escribe su primer drama, tiene veintitrés años y una magnífica tradición viva es Lope de Vega, Guillén de Castro, Mira de Amescuá, Vélez de Guevara, Ruiz de Alarcón, Tirso de Molina. El drama de honor ha obtenido los aplausos del público de los corrales, y para un autor que pretenda añadir algo al género, sólo queda la posibilidad de alambicarlo, dar perfil y coherencia a la profusión de "casos de honra" que han inundado el teatro. Calderón trae una voluntad de lucidez a la dramaturgia, y por eso mismo problematiza el género en curso. La vida es sueño es, ante todo, una interrogación, y también una respuesta -la de Calderón-, sobre el drama de honor, entendido esta vez fuera de los límites escénicos de la obra; problematismo arrojado sobre los mismos valores que hicieron históricamente posible ese teatro. La vida es sueño es el drama de honor tomando conciencia de su dramatismo.

La problematización se asevera, abruptamente, ya desde el título; la respuesta es precisamente el desenlace al que la trama conduce por los pasos de un argumento escolástico. La oposición del problema a una solución que difícilmente puede convencer a la sensibilidad del siglo XX, ha sido la causa de que hispanista tan eminente como Arturo Farinelli viera la obra como elemental contradicción ${ }^{20}$. La vida es sueño -dice Farinelli- propone una tesis escéptica; la conformidad religiosa al bien obrar, sin más apoyo para esa elección que el sueño de donde surge, parece introducir una antítesis, para la cual la síntesis calderoniana no es otra cosa que un compromiso con la moral. El mismo compromiso se aprecia en Descartes, a quien nadie, que yo sepa, ha acusado de incoherencia. Pero además, es importante tener en cuenta el sentido platonizante de la aseveración calderoniana. "La vida es

19. Francisco Ruiz Ramón, Historia del teatro español, vol. I, Alianza editorial, Madrid 1967, p. 187.

20. Arturo Farinelli, La vita è un sogno Parte seconda (Torino, 1916), pp. 283-284. Citado por E.M. Wilson, "On La vida es sueño", Critical Essays on the theatre of Calderón, ed. by Bruce W. Wardropper, New York University Press, 1965, p. 67. 


\section{HONOR Y RAZON EN "LA VIDA ES SUEÑO"}

sueño" equivale en Calderón a "esta vida es sueño" en contraste con la otra vida, con la del despertar. Y este despertar, veremos, no es otro que la irrupción en la moralidad. Dicho en términos platónicos: despertar es mirar el Bien. Así, pues, se esfuma la contradicción.

Añadamos que el aprendizaje de Segismundo no se limita nunca a una asimilación de razones. Fundamental para su desarrollo es su iniciación práctica o vital en el bien; iniciación que, una vez más, platónicamente, arranca de la percepción de la belleza.

Segismundo. Y aunque en desdichas tan graves
la política he estudiado,
de los brutos enseñado,
advertido de las aves,
y de los astros süaves
los círculos he medido:
tú sólo, tú has suspendido
la pasión a mis enojos,
la suspensión a mis ojos,
la admiración a mi oído ${ }^{21}$.

Jor. I, II, 213-222.

Menéndez Pelayo perdió el sentido de la obra al considerar la relación Segismundo/Rosaura (perfectamente trenzada con las oposiciones Segismundo/Basilio y Rosaura/Astolfo, complementarias entre sí) como "Una intriga extraña, completamente pegadiza y exótica, que se enreda a todo el drama como una planta parásita ${ }^{22}$ ". Al no comprender lo esencial de la relación entre ambos protagonistas, victimizados uno y otro por inmutables principios rectores de las vidas particulares (los astros, el honor), tampoco pudo percibir el tránsito sutil y cuidadoso del Segismundo primario, más fiera que hombre, al Segismundo modelo de príncipes, hombre que ha vencido a la fiera. Y así escribió lo que hoy parece inverosímil ceguera para el desarrollo dramático de esta obra:

En Calderón hay un salto mortal desde el Segismundo siervo y juguete de la pasión hasta el Segismundo tipo del príncipe perfecto, que aparece en la tercera jornada ${ }^{23}$.

21. Para las citas de La vida es sueño utilizo la edición de José Martel y Hymen Alpern, revisada por Leonard Mades, en Diez Comedias del Siglo de Oro, $2^{\mathrm{a}}$ edición, Harper \& Row, New York, 1968.

22. M. Menéndez y Pelayo, Calderón y su teatro, I, Madrid, 1910, p. 278. Cit. por Wilson, op. cit., p. 66.

23. M. Menéndez y Pelayo, op. cit., p. 276. Cit. Wilson, op. cit., p. 66. 


\section{JUAN RAMON RESINA}

La estructura platónica de La vida es sueño asegura la gradual conversión del protagonista. Aunque desde el principio domina la técnica del silogismo, Segismundo aparece inmerso en el caos de las sensaciones, sin comprender la especial categoría en que le sitúa la sensación de sí por razón de su naturaleza humana. Segismundo compara su suerte con la de los demás seres de la creación, sin comprender su radical condición de hombre, a la vez inmerso y ajeno a la libertad necesaria del río, el pez, el bruto y el ave. La inconsciencia es la tumba de Segismundo, en el más estricto sentido gnóstico del soma sema (el cuerpo es una tumba). Así Rosaura puede decir:

$$
\begin{aligned}
& \text { Sí, pues a sus reflejos } \\
& \text { puedo, determinar, aunque de lejos, } \\
& \text { una prisión obscura, } \\
& \text { que es de un vivo cadáver sepultura; } \\
& \text { y porque más me asombre, } \\
& \text { en el traje de fiera yace un hombre } \\
& \text { de cadenas cargado, } \\
& \text { y sólo de una luz acompañado. }
\end{aligned}
$$

Jor. I, II, 91-98.

Esta luz, con la que nace cada hombre, es el principio de libertad, facultad de conocimiento y único instrumento capaz de quebrar las cadenas que someten al hombre. Prisión y condición animal son una misma cosa, y ambas perduran en tanto le falta a Segismundo una referencia exterior a sí mismo, algún objeto humano que pueda ser iluminado por la luz de su razón, y que le permita, por oposición, tomar conciencia de la humanidad de la cual él participa.

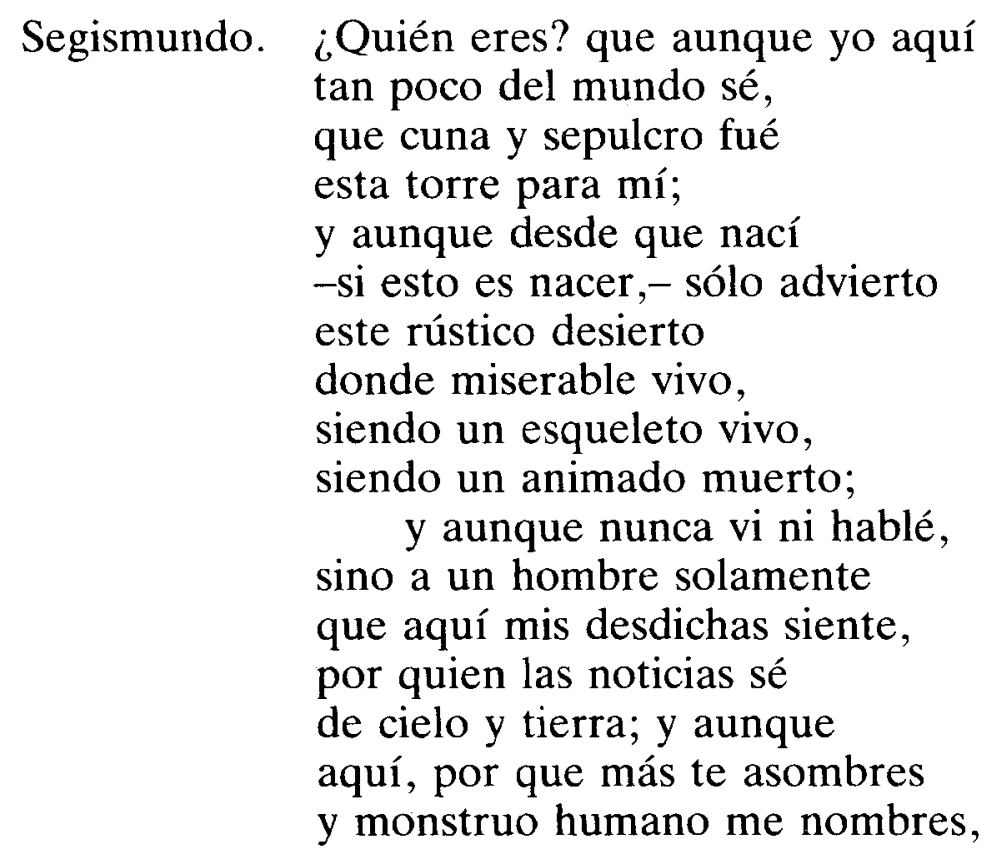




\section{HONOR Y RAZON EN “LA VIDA ES SUEÑO”}

entre asombros y quimeras, soy un hombre de las fieras, y una fiera de los hombres.

Jor, I, II, 193-212.

Rosaura será la referencia exterior que hará posible la toma de contacto del hombre consigo mismo (hombre de los hombres), a través de la experiencia del amor. Ella, o más exactamente, su belleza, despierta por primera vez el ansia de racionalidad de Segismundo.

William M. Whitby ha señalado que el desengaño de la experiencia de los sentidos no se produce en Segismundo a raíz de la comedia de la libertad practicada en la corte.

The premises on which he (Segismundo) has based this view of life (la vida es sueño) are false ones, the result of a deception contrived by Clotaldo and Basilio. Conflicting with this view of life is another, more practical one. In this view, he considers his prison existence reality -waking- and his palace stay illusion-dreaming. Because he also holds this other view, he refuses at first to go with the soldiers when they come to free him. They are not real, he thinks, but shadows which his deceitful senses conjure up. What he has learned up to this point is that his senses are not to be trusted $^{24}$.

Lo que decide a Segismundo a seguir a los soldados es el hecho de poseer un asidero a la realidad, un tablón de certidumbre en medio de la confusión. La belleza de Rosaura había producido en él un estado anímico más duradero que la sensación; estado que no se ha evaporado en el tránsito de la libertad de la corte a la esclavitud en la torre:

$\begin{array}{ll}\text { Segismundo. } & \text { De todos era señor, } \\ \text { y de todos me vengaba; } \\ \text { sólo a una mujer amaba... } \\ \text { Que fué verdad, creo yo, } \\ \text { en que todo se acabó, } \\ \text { y esto sólo no se acaba. }\end{array}$

Jor. II,XVIII, 2132-2137.

Segismundo siente que la impresión de la belleza, y la humanización que evoca en él, son sus únicas certidumbres. Es como respuesta a la experiencia de un orden nuevo, ajeno a la necesidad animal y manifiesto en la

24. William M. Whitby, "Rosaura's Role in the Structure of La vida es sueño", Critical Essays on the theatre of Calderón, op. cit., pp. 103-104. 


\section{JUAN RAMON RESINA}

belleza de Rosaura, que Segismundo traba contacto con la libertad, reprimiendo una espontaneidad que es sujeción a la fatalidad del bruto (fiera de los hombres). La presencia de Rosaura apela a su humanidad. Así, cuando Segismundo va a dar cauce a su violencia espontánea, Rosaura le detiene con sugerirle su verdadera naturaleza:

$$
\begin{array}{ll}
\text { Rosaura. } & \multicolumn{1}{c}{\text { Si has nacido }} \\
\text { humano, baste el postrarme } \\
\text { a tus pies, para librarme. } \\
\text { Segismundo. } & \text { Tu voz pudo enternecerme, } \\
\text { tu presencia suspenderme } \\
\text { y tu respeto turbarme. }
\end{array}
$$

Jor. I, II, 187-192.

La progresión platónica de la belleza al bien garantizará en sus sentimientos el de que también el bien, esto es, la moral, es eterna.

Rosaura es el objeto amoroso que alumbra la luz de la razón en Segismundo. Este, que no distingue todavía entre la potencia y el acto, confunde a Rosaura con la luz que arde en sí mismo:

Oye, mujer, detente:

no juntes el ocaso y el oriente, huyendo al primer paso;

que juntos el oriente y el ocaso,

la luz y sombra fría, serás sin duda síncopa del día.

Jor. II, VII, 1572-1577.

De los cinco epítetos que Segismundo aplica a Rosaura, cuatro son referencias luminosas:

...habiendo sido

por más bella y hermosa,

sol, lucero, diamante, estrella y rosa?

Jor. II, VII, 1615-1617.

Cuando ella hace por irse, Segismundo le dice:

No has de ausentarte, espera.

¿Cómo quieres dejar de esa manera

a oscuras mi sentido?

Jor. II, VIII, 1624-1626. 
William M. Whitby ha observado muy bien la progresión desde la sola luz que acompaña a Segismundo en la primera jornada hasta el esplendor de la razón adquirida:

In the first act, then, when Segismundo is immersed in the shadows of his spiritual night, Rosaura arouses his desire to see. In the second act, he tries to keep the light which her presence brings to him. But he is unable to do this, relying as he does not on reason but on physical force. In the third act, when he "comes forth to the day of his deeds from the night of his shadows," the light which he receives from Rosaura is there is blinding strength ${ }^{25}$.

En efecto, en la jornada tercera, cuando Segismundo ve venir a Rosaura sin reconocerla todavía, la impresión de luminosidad rebosa del alma de Segismundo:

Su luz me ciega (Jor. III, IX, 2687).

Segismundo corre constantemente el peligro de zozobrar y recaer en los impulsos que coartan su libertad de ser racional que dispone de su voluntad. Como compuesto de hombre y fiera, está capacitado para responder a la belleza de la mujer con una afirmación de su propia humanidad (lo cual implica, en su caso, sumisión a la voluntad de la mujer y a las normas que definen y determinan las relaciones humanas), o bien, afirmando a la fiera, al despreciar la racionalidad que preside idealmente las relaciones entre hombres, y poner en peligro las vidas ajenas.

No tiene razón Maraniss cuando considera que la unión de Segismundo y Rosaura ha sido impedida para que prevalezca una razón de estado ${ }^{26}$. Concebir de este modo la resolución de Segismundo es ignorar que el honor ha sido vivido con verdadera pasión por los españoles del siglo XVII. Es ignorar las bases mismas de la vida española del mil seiscientos. El honor no es una superestructura ni una norma descendida desde arriba sobre los españoles de esa época; por el contrario, es una exigencia que asciende desde abajo y que a menudo se vuelve contra los de arriba, como acontece con la "compañía de los hidalgos cansados", cuya limpieza de sangre es puesta en duda por Constanza y por Belardo, que los llama explícitamente "judíos" en la jornada tercera, escena sexta, de Peribánez. El honor en el siglo XVII se ha convertido en España en un haz de rasgos étnicos, morales e históricos, cuya posesión o pérdida determina el ser y la identidad de las personas. El honor no era impuesto a los campesinos -claros e indiscutibles detentadores de la pureza de sangre- por razón de estado. Fue el campesino castellano quien

25. Ibid., pp. 103-104.

26. James E. Maraniss, On Calderón, University of Missouri Press, Columbia \& London, 1978. 


\section{JUAN RAMON RESINA}

hizo valer esa noción contra valores aparentemente más firmes, como la riqueza, la habilidad intelectual, el encumbramiento social. Cuando Segismundo reconoce a Rosaura el derecho a recuperar su honor (nótese que esta satisfacción, y no la unión con Segismundo, es siempre el primer deseo de Rosaura), el príncipe no tiene conciencia de reforzar, con su gesto, los cimientos de su estado. La intención y el efecto inmediato de su renuncia es devolver a la mujer el ser social que había perdido, y por un acto creador no exento de amor, instituirla en la perfección de la identidad con los valores que apuntalan su conciencia. Si estos valores son incoherentes con los postulados románticos, no lo son en menoscabo de Calderón, sino del crítico que pretende someter los unos a los otros. De haber entrevisto Maraniss que la renuncia de Segismundo entrañaba amor mezclado con respeto por Rosaura, hubiera encontrado que no hay inconsecuencia lógica entre la renuncia a la mujer y la defensa de su honor.

Segismundo's decision to renounce his attraction to Rosaura in order to cleave unto the eternal (" ¿Quién por una gloria humana/ pierde una divina gloria?") need not necessarily lead him to become her champion nor to begin adopting the restraints that had been working upon him from the outside. It does not follow, at least from what the reader is given to know of Segismundo's involvement with Rosaura, that he should all at once become the guardian of the established order ${ }^{27}$.

Pues Segismundo no renuncia a Rosaura por motivos ascéticos. La "divina gloria" no tiene nada que ver aquí con la mortificación de la carne. Su renuncia es el paso necesario para la restitución del honor de Rosaura, y sólo tiene sentido y se realiza con vistas a esta finalidad. Más exactamente: Segismundo se constituye en guardián del código del honor por amor de Rosaura, respondiendo a la súplica de la mujer amada:

Mujer vengo a persuadirte al remedio de mi honra, y varón vengo a alentarte a que cobres tu corona.

Jor. III, X, 2902-2905.

Y en última instancia, la renuncia de Segismundo está anticipada en la de Rosaura, que es la primera (y quizás la única) en deponer el amor para someterse a la necesidad del honor, que confundido con el orden racional, es el factor decisivo en la recuperación del hombre en cuanto hombre: Segismundo convertido en príncipe; Rosaura apareciendo en su verdadera iden- 


\section{HONOR Y RAZON EN "LA VIDA ES SUEÑO”}

tidad tras la anagnórisis de la escena $X$ en la jornada tercera, en que revela su linaje y su historia, y después de que, gracias a la renuncia de Segismundo, deja de ser "monstruo de una especie y otra" (jornada III, X, 2725), para en adelante llevar sólo "galas de mujer". La renuncia de Rosaura decide la actuación de Segismundo al definir el orden de preferencias que va, jerárquicamente, de lo real ("lo eterno/que es la fama vividora", jor. III, X, 2978-79) a lo soñado (el gusto, "llama hermosa,/ que la convierte en cenizas/ cualquiera viento que sopla", jor. III, X, 2975-77):

Y así piensa, que si hoy

como mujer me enamoras

como varón te daré

la muerte en defensa honrosa

de mi honor, porque he de ser

en su conquista amorosa,

mujer para darte quejas,

varón para ganar honras.

Jor. III, X, 2910-2917.

Es precisamente a la luz de esta renuncia compartida, que me parece lamentable la conclusión de Maranis sobre la naturaleza del amor de Segismundo. La función mistagógica del amor, concebida por Calderón en términos platónicos como una iniciación al bien, no concuerda en absoluto con la degradación del sentimiento que expresa Maraniss, cuando dice de Segismundo que "His attraction to Rosaura has been, on the whole, bestial, and when not bestial, illusory" 28 . La realidad del amor para Segismundo es explícita:

Sólo a una mujer amaba...

Que fué verdad, creo yo,

en que todo se acabó,

y esto sólo no se acaba.

Jor. II, XVIII, 2134-2137.

Segismundo no es inconsciente de lo que pierde al renunciar a Rosaura. Esa renuncia es para él "la más alta" de sus "grandes victorias" (jor. III, XIV, 3251-3257). Maraniss tampoco tiene razón cuando expresa con sentido generalizable, no circunscrito a su gusto personal, "the sense of dissatisfaction one feels at Calderón's sudden abandonment of the erotic action he has begun" 29 . Esto es, una vez más, juzgar al autor por lo que no entra en sus designios. El drama de honor no es lo mismo que el drama romántico, donde

28. Ibid., p. 39

29. Ibid., p. 40 
el problema del honor se resuelve en matrimonio. Ni siquiera Lope -a quien Maraniss antepone a Calderón por su interés erótico- satisface las expectativas del lector de novelas amorosas. Piénsese en obras como El mejor alcalde el Rey, Fuenteovejuna, El caballero de Olmedo, donde la acción erótica, una vez ha creado expectativas en el público, se ve bloqueada por la verdadera problemática de este teatro: los casos de honor en las dos primeras obras, y algo que se aproxima a la fatalidad trágica en El caballero de Olmedo. Es el honor, verdadera premisa del amor en el teatro español del siglo XVII, lo que impide la reunión final de Rosaura y Segismundo. Esa reunión no podría realizarse sin violentar el honor y la integridad de Rosaura, y en consecuencia, la recién conquistada humanidad de Segismundo.

Corresponde a grosera observación hablar de "reduced humanity" acerca de Segismundo, a consecuencia de su renuncia a la posesión de Rosaura $^{30}$. El estadio inicial de Segismundo corresponde a la mitad animal que el príncipe ha percibido en sí. Por el contrario, la parte humana, racional, es potenciada con su acceso a la conciencia de la irrealidad de la vida, y su opción moral, constructora o reconstructora de un orden humano, el único indudable en el centro de la ambigüedad del mundo. El yo pensante de Descartes es aquí el yo actuante, moral, de Segismundo.

Corresponde ahora analizar los valores sobre los que descansa el orden que da sentido a la humanidad de Segismundo. Tampoco en la apreciación de estos valores puedo sentirme cómodo con las opiniones de Maraniss, quien se halla siempre dispuesto a demostrar, sin paliativos, el carácter reaccionario de Calderón. Según él, éste se expresa no sólo en las soluciones dramáticas, sino en la misma coherencia del lenguaje y la técnica utilizados ${ }^{31}$. Escribe Maraniss: "Calderón's readers will always have sympathy for what is renounced, as long as liberty and love and life are valued; but to Calderón, order is a higher value than any of these".

Esto es extraordinariamente endeble. La vida es sueño constituye toda ella una crítica de la sumisión al orden ciego. La desgracia es desencadenada por el sometimiento de Basilio al orden extrahumano de las leyes cósmicas. La redención se produce al tomar contacto Segismundo con la dimensión libre de su persona. Incluso la restauración de un orden -que en las tragedias es posible sólo con la purga que hace desaparecer al héroe, origen del desequilibrio e incapaz de zafarse de su destino- aparece aquí como elección indeterminada por necesidades de orden externo a la volición y el asentimiento. Los valores afirmados son (parcialmente) critianoș. Acaso no sustentan ya el mundo en que nosotros vivimos; pero esos valores -el bien, la humildad, la templanza- han de aparecer necesariamente como absolutos desde el momento que lo son, no sólo para Segismundo, sino para Calderón

30. Ibid., p. 41.

31. Ibid., p. 100 
mismo, y para cualquier autor español de la época. La adopción incuestionada de estos valores, la convicción con que son tomados por patrón del comportamiento, pertenece al orden de las creencias, al subsuelo que sostiene a estos autores, no al de las ideas que pueden ser manejadas y sometidas a crítica. Afirmando estos valores, Calderón no da apoyo a un orden político determinado, no concibe sus obras "por razón de estado". Exceptuando el principio del honor, cuya expresión en el siglo XVII, amortiguada su influencia en el resto del continente europeo, le define como español, los valores que concurren en la formación del príncipe perfecto son los principios axiológicos de toda nación europea contemporánea del dramaturgo.

Hemos hablado del subsuelo de creencias que sostiene a Calderón y sus contemporáneos. Es hora de abordar la cuestión de la radicalidad con que Calderón se interrogó sobre la realidad -es decir, sobre la validez de la fundación- de su mundo. ¿Es correcto sugerir que practicó de hecho esta inquisición, cuando el resultado de percibir la inanidad de la vida es aherrojarla con la moral instituida? El triunfo de la moral (entendida como distinta del bien, no como razón sino como reglamento), manifiesto más en el castigo del soldado rebelde que en la reivindicación del honor de Rosaura, es de hecho una flaqueza del espíritu del príncipe cristiano. Podría pensarse que Segismundo, que ha sido rebelde en palacio, atentando contra la armonía preestablecida de la etiqueta cortés y destruyendo el reglamento impuesto por el mismo orden que hace posible su reinado, debería ceñirse a la ética propugnada por Rosaura, y que fácilmente se supondría coincidente con la del autor:

juez que ha sido delincuente, ¡qué fácilmente perdona!

Jor. III, X, 2824-2825.

De la misma ética participa Segismundo:

que toda la dicha humana en fin pasa como un sueño, y quiero hoy aprovecharla el tiempo que me durare: pidiendo de nuestras faltas perdón, pues de pechos nobles es tan propio perdonarlas.

Jor. III, XIV, 3309-3315.

Siendo éste su modo de sentir, ¿por qué restituye la torre, y con ella el régimen que antes ha sido injusto con él? La respuesta se nos impone: La experiencia de la torre ha sido para Segismundo la de la ignorancia, el estadio animal en que el hombre se desconoce a sí mismo. Alcanzar la libertad 
equivale, en la concepción calderoniana del mundo, fundamentar el ser sobre la racionalidad, único valor real en que el hombre debe apoyarse para salir del sueño de los impulsos. Toda regresión a la confusión que antecede a la configuración social (configuración que deriva de la discreción y prudencia, y se entrelaza con el perpetuo temor a la confusión originaria) equivale a recaer en la "prisión obscura", en el "traje de fiera" con que descubrimos a Segismundo al comenzar la obra. En cierto sentido, puede decirse que la caída en prisión está implícita en la caída en confusión, en la "causa/ del alboroto del reino" (jor. III, XIV, 3289-3290) que ha sido el soldado; y que Segismundo, condenándolo, no ha hecho sino dibujar dramáticamente un movimiento que Calderón entiende filosóficamente. Por último, siendo el recuerdo y el temor de la torre lo que mantiene en vilo la prudencia actual de Segismundo,

Segismundo. ¿Qué os admira? ¿qué os espanta,
si fué mi maestro un sueño,
y estoy temiendo en mis ansias
que he de despertar y hallarme
otra vez en mi cerrada
prisión?

Jor. III, XIV, 3301-3306.

no sorprende que la institución de la torre se considere fundamental para mantener la lucidez alcanzada por el ser humano. Evidentemente, esta dialéctica se inserta en una visión autoritaria de la organización social, y justifica que se haya considerado reaccionaria la psicología de Calderón, que no lo es ni más ni menos que toda otra psicología orientada por la dualidad pre$\mathrm{mio} /$ castigo.

Nos engañaríamos con suponer que la afirmación final de los valores tradicionales obedece a una falsa o superficial interrogación sobre la realidad de la existencia, así como sobre la validez de la moralidad que rige las relaciones humanas. Comentando el soliloquio de Segismundo:
¿Qué es la vida? Un frenesí.
¿Qué es la vida? Una ilusión.
Una sombra, una ficción.
Y el mayor bien es pequeño;
que toda la vida es sueño, y los sueños sueños son.

el ensayista inglés G.H. Lewes ha escrito:

This is a fine burst of poetry, but the philosophy is neither new nor true; and if it were true, if this life were all illusion, all a 
sick and troubled dream, would not the task of the philosopher still be the same -to discover our relations to the universe and to each other? ${ }^{32}$.

La filosofía no es nueva, por supuesto; se trata de uno de los temas constantes en la literatura española: la fugacidad presta a la vida esa inanidad propia de los sueños. Lo original en Calderón es la radicalidad con que se presenta esa filosofía tantas veces repetida y asimilada por la conciencia española, hasta el punto de hacer muy difícil para el poeta y el dramaturgo el recurso al tema con cierto margen de sorpresa y de frescura. En conseguir éstas, Calderón ha mostrado gran habilidad, y es absurdo apuntar como demérito el uso de una filosofía ancestral, que volvería a ser utilizada con originalidad y fuerza por Schopenhauer en el siglo XIX. Sobre la verdad de esta filosofía no podemos discutir sin recurrir, por nuestra parte, a un análisis filosófico que, inevitablemente, derivaría hacia la metafísica. Imponer nuestra opinión sin justificarla, como ha hecho Lewes, quitaría a nuestras palabras todo valor argumentativo. En cambio, sí podemos discutir con Lewes, por hallarse dentro de la materia misma del drama, la aseveración de que, en vista de una realidad cercenada, Calderón se ha limitado a aceptarla sin indagar, dentro del sueño, las relaciones que mantienen la coherencia de éste.

Pues es evidente que la relación con el cosmos ha sido explorada. Al experimento de Basilio sigue el descubrimiento de que, la fuerza que liga al hombre con el universo no es el determinismo impasible, simbolizado por los astros. La voluntad humana es rectora de la configuración del sueño de la vida y de la historia, y en esto Calderón se acerca considerablemente a Schopenhauer -en el énfasis en la voluntad humana, en tanto que a la visión medieval hubiera correspondido la voluntad divina. Tampoco en esto es nuevo Calderón. En la Comedia segunda de Las mocedades del Cid, Guillén de Castro ha hecho decir al segundo morabito:

$$
\begin{aligned}
& \text { Assí está escrito en el cielo. } \\
& \text { Mas tu cuydado y prudencia } \\
& \text { vencerá a la Astrología, } \\
& \text { porque es la sabiduría } \\
& \text { más fuerte que la influencia. }
\end{aligned}
$$

Acto II.

32. George Henry Lewes, Spanish Drama: Lope de Vega and Calderón, p. 176. Citado por Maraniss, op. cit., p. 33. 
Y así Clotaldo repite:

Aunque el hado, señor, sabe todos los caminos, y halla a quien busca entre lo espeso de las peñas, no es cristiana determinación decir que no hay reparo a su saña. Sí hay, que el prudente varón victoria del hado alcanza; y si no estás reservado de la pena y la desgracia, haz por donde te reserves.

Jor. III, XIII, 3108-3118.

La inescrutabilidad de las razones divinas coloca a los humanos en primer término, de modo que el hombre se convierte en principio de sus actos, en motor movido por su voluntad.

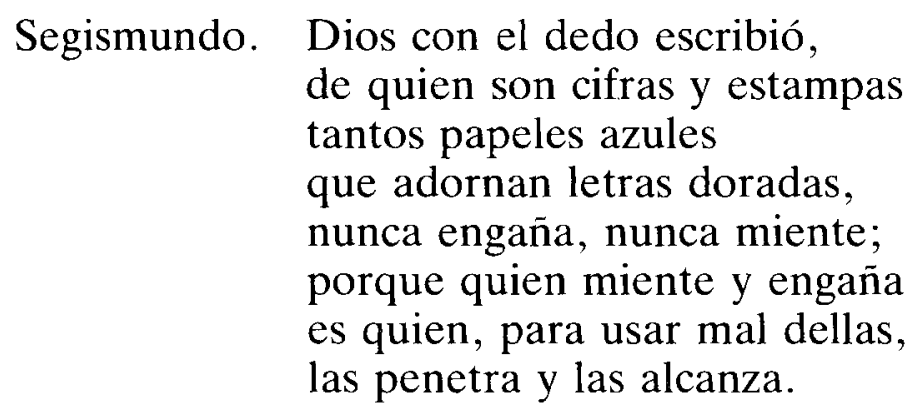

Jor. III, XIV, 3160-3167.

En cuanto a indagar las relaciones que rigen entre los hombres, no parece haber leído La vida es sueño quien echa de menos en la obra la exploración de las relaciones humanas. Estas se insertan perfectamente en el terreno de la moral, y siendo ésta la materia que traspasa a la obra, sorprende por lo disparatado la sugerencia de que se haya pasado por alto este aspecto de la vida. Ahora bien, Calderón problematiza la moral. El experimento de Basilio está diseñado para observar la posible alteración del comportamiento bajo condiciones distintas. Pero a Basilio, cuya confianza en la voluntad humana es tan escasa que ha preparado de antemano el plan para devolver a su hijo a la prisión, le ha faltado penetrar en la más sutil de las verdades elaboradas por Calderón. A toda su ciencia ha escapado el hecho fundamental de que la voluntad necesita insertarse en el amor para ascender a un conocimiento superior, capaz de fundar las relaciones sobre los pilares de una racionalidad característicamente humana. A Segismundo no le ha bastado con acumular conocimientos para humanizarse; la belleza de Rosaura y oír por primera vez una apelación a su humanidad: 


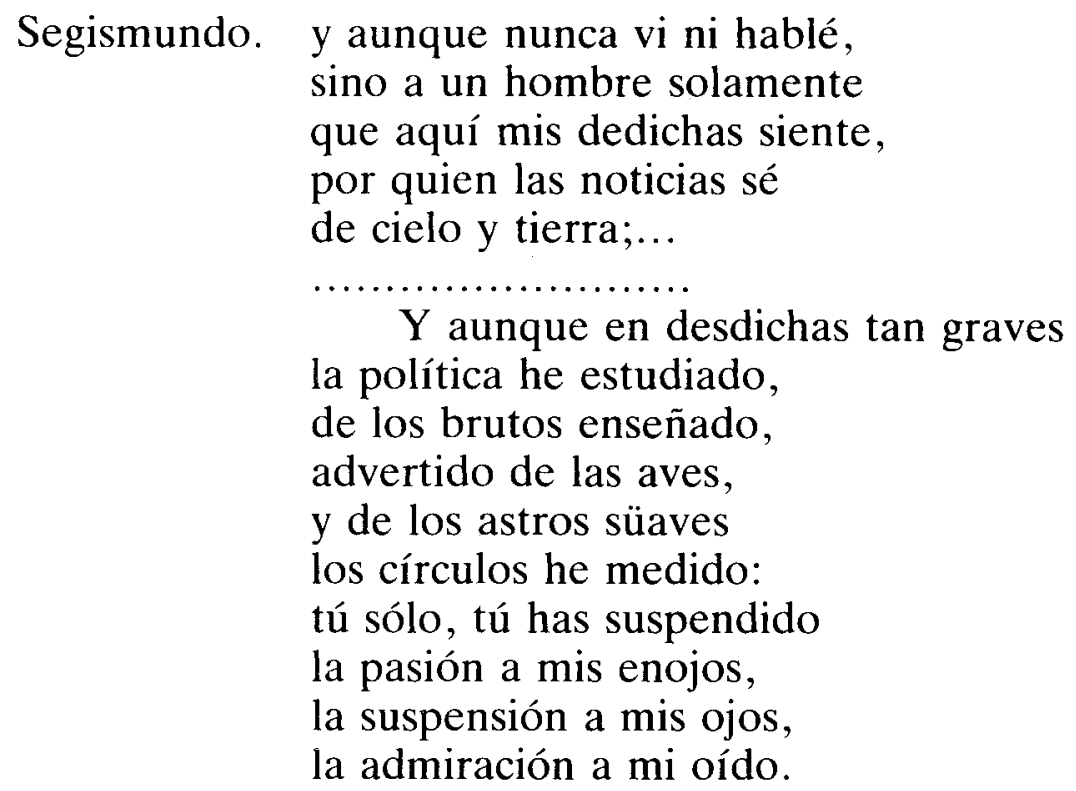

Jor. I, II, 203-207; 213-222.

Por ello mismo, lo realmente importante de su descubrimiento no es la inanidad de la vida, la rapidez con que se disipan las dichas, sino el contraste que se da entre esta fragilidad y la perdurabilidad -también descubierta por él- del amor que en él ha depositado Rosaura. Más adelante Calderón cede a la coacción de su época, y sustituye esta impresión original de Segismundo por el ídolo de la opinión, que siendo mostrenca, difícilmente podría corresponder a ùna vivencia interior del individuo.

$$
\begin{aligned}
& \text { acudamos a lo eterno, } \\
& \text { que es la fama vividora }
\end{aligned}
$$

Jor. III, X, 2978-2979.

La prioridad concedida a la fama sobre el sentimiento responde a la preferencia de lo objetivo sobre lo subjetivo, de lo social sobre lo íntimo, propia del espíritu castellano. La fama es lo que acompaña a las acciones sancionadas por el sentido ético de la comunidad, sentido íntimamente imbricado con las costumbres privativas del grupo.

El descubrimiento original de Segismundo no se ha detenido en el momento contemplativo. Al salir por segunda vez de la torre, los acontecimientos y su propia voluntad le lanzan a la acción, que se desempeñará siguiendo esta vez la única opción de civilización que tiene ante sí. El descubrimiento de sí mismo lleva a Segismundo lejos de la contemplación:

Rosaura. Generoso Segismundo, cuya majestad heróica sale al día de sus hechos 


\section{JUAN RAMON RESINA}

de la noche de sus sombras;

Jor. III, X, 2690-2693.

Segismundo. No te responde mi voz, porque mi honor te responda;

no te hablo, porque quiero que te hablen por mí mis obras,

Jor. III, X, 3004-3007.

Con ello Segismundo rompe las tenazas de una estructura social fundamentalmente represiva de la acción, pues su percepción de la capacidad de la voluntad para estructurar el sueño hace ineficaz el gravamen de la ideología inmovilista suscitada por los poderes sociales. En comprender esto se ha mostrado perspicaz Edwin Honig, quien, refiriéndose a Basilio y Clotaldo, escribe:

Their special counsel is against action, for they use the formula of life-is-a-dream in the narrowest sense, as a palliative, in order to civilize, taunt, even torment (read tame) the prince. But Segismundo's only chance to achieve his own identity is by recognizing that the formula refers to his unborn condition. This he must discover before he can be regenerated ${ }^{33}$.

La tesis de Honig se ve ofuscada por los despropósitos freudianos que aplica a las relaciones entre Rosaura y Segismundo y entre éste y Basilio. Si lo que el rey combate encerrando a su hijo es "the blind fear of the succession of life", ¿por qué prepara la sucesión en los sobrinos, hallándose bien dispuesto a ceder el trono? Pero acierta plenamente al distinguir entre la sociedad autoritaria, que sirve de fondo a la problemática suscitada por Calderón, y las soluciones aportadas por éste, no como revolucionaria sacudida de la estructura de la sociedad en que vive, sino como modificación de la actitud con que el hombre (y el monarca) sometido a un haz de nociones tradicionales puede alterar los efectos derivados de la rigidez de principios. De esta obra Honig hace resaltar "its persistent exploration of the human virtues of clemency, love, and magnanimity, held up against the combative principle of the strict honor code- the power drive, vengeance, absolute laws" ${ }^{34}$.

En la segunda jornada de La vida es sueño, Calderón ha imaginado un mundo entregado, no al desorden, como cree Maraniss ${ }^{35}$, sino a un orden

33. Edwin Honig, Calderón and the Seizures of Honor, Harvard University Press, Cambridge, Mass., 1972, p. 163.

34. Ibid., p. 175.

35. "One does not read Calderón to find out about the world, or the reason, or human appetites; one reads Calderón to experience his tortured and unseccessful attempt to make what is unreasonable seem reasonable and to put up some sort of defense against and ever-present and barely controllable will to disorder".Maraniss, op. cit., p. 39. 
ajeno a la voluntaa numana, cuya capacidad para crear un orden justo depende del grado de conciencia racional alcanzado por el individuo. El conocimiento imperfecto del estudioso rey Basilio ha sido ocasión de injusticia y de rebelión en el reino. La superior racionalidad alcanzada por su hijo, el platonizante príncipe-filósofo, augura un reinado instituido sobre la conquistada humildad, verdadera prudencia del príncipe cristiano. Los efectos que se desprenden de una voluntad desestribada son desastrosos. En el mundo de la libertad Segismundo se conduce como un prisionero sin cadenas; es la misma fiera que hemos visto sometida en la torre. Aun cuando el modelo de civilización propuesto por el dramaturgo no es otro que el de su época, y su modelo de príncipe obedece al que propone Santo Tomás en De Regimine Principium ${ }^{36}$, Calderón descubre que su fundamentación es imposible desde arriba, que la superestructura social fracasa allí donde las potencias afectiva y racional del individuo no han sido agitadas por una apelación a lo que de humano hay en el "compuesto de hombre y fiera".

36. Ver el ensayo de Everett W. Hesse, "Calderón's concept of the Perfect Prince in La vida es sueño", en Critical Essays, op. cit., p. 115. 
